\title{
The Value of GRE, ADC and Routine MRI in Distinguishing Parkinsonian Disorders
}

\author{
Pettarusp M. Wadia, Peter Howard, Manuel Q. Ribeirro, Jennifer Robblee, \\ Abena Asante, David J. Mikulis, Anthony E. Lang
}

\begin{abstract}
Objectives: To study different radiological signs and sequences including apparent diffusion coefficient (ADC) and gradient echo (GRE) to differentiate degenerative parkinsonian syndromes. Background: Multiple system atrophy (MSA), Parkinson's disease (PD), progressive supranuclear palsy (PSP) and corticobasal degeneration (CBD) differ in the pattern of neurodegeneration and cellular damage. Measuring the ADC, GRE sequences for paramagnetic substances and simple anatomical assessments have been reported individually to assist in separating some of these disorders, but have not been compared. Methods: Brain MRIs from May 2002 to February 2008 were retrospectively evaluated by raters blinded to the clinical diagnosis for predefined MRI signs on T1, T2 and GRE sequences. ADC values were quantitatively measured. Medical records were objectively analyzed using standard clinical criteria for different parkinsonian syndromes. Results: 195 cases comprising of 61 PD, 15 MSA-P, 7 MSA-C, 21 PSP, 6 Corticobasal syndrome, 21 not fitting criteria and 64 controls were evaluated. 73\% of patients with MSA-P had hypointensity of the putamen (compared to the pallidum) on GRE. The specificity of this sign to diagnose MSA-P was 90\% versus PD and 76\% versus PSP. When GRE hypointensity was combined with atrophy of the putamen the specificity improved to $98 \%$ (versus PD) and 95\% (versus PSP) without altering the sensitivity. The ADC values were significantly higher in the middle cerebellar peduncle in cases with MSA-C versus controls, PD and PSP ( $<<0.001)$. Conclusions: The combination of hypointensity and atrophy of the putamen on GRE is useful in differentiating MSA$\mathrm{P}$ from other parkinsonian syndromes.
\end{abstract}

RÉSUMÉ: La capacité de l'ÉG, du CDA et de l'IRM faits de routine à distinguer les différents troubles parkinsoniens. Objectif : Le but de l'étude était d'examiner les différents signes et les différentes séquences radiologiques, dont le coefficient de diffusion apparent (CDA) et échos de gradient (ÉG) pour différencier les syndromes parkinsoniens dégénératifs. Contexte : Les caractéristiques de neurodégénérescence et de dommage cellulaire sont différentes dans l'atrophie multisystémique (AMS), la maladie de Parkinson (MP), la paralysie supranucléaire progressive (PSP) et la dégénérescence cortico-basale (DCB). Des mesures du CDA, des séquences ÉG des substances paramagnétiques ainsi que des évaluations anatomiques simples ont été rapportées séparément pour aider à distinguer certaines de ces maladies, mais elles n'ont jamais été comparées entre elles. Méthode : Des évaluateurs ont revu rétrospectivement les IRM du cerveau effectuées entre mai 2002 et février 2008, sans connaître le diagnostic clinique posé chez les patients, afin d'identifier des signes prédéfinis à l'IRM en T1, en T2 et dans les séquences ÉG. Les valeurs du CDA ont été mesurées quantitativement. Les dossiers médicaux ont été analysés objectivement au moyen des critères cliniques standards des différents syndromes parkinsoniens. Résultats : Cent quatre-vingt-quinze cas dont 61 cas de MP, 15 cas d'AMS-P, 7 cas d'AMS-C, 21 cas de PSP, 6 cas de syndrome corticobasal, 21 cas qui ne rencontraient pas les critères standards et 64 témoins ont été évalués. Soixante-treize pour cent des patients atteints d'AMS-P avaient de l'hypointensité au niveau du putamen par rapport au pallidum à l'ÉG. La spécificité de ce signe pour le diagnostic de l'AMS-P était de $90 \%$ par rapport à la MP et de 76\% par rapport à la PSP. Quand l'hypointensité à l'ÉG était combinée à l'atrophie du putamen, la spécificité s'élevait à 98\% par rapport à la MP et à 95\% par rapport à la PSP, sans en modifier la sensibilité. Les valeurs du CDA étaient significativement plus élevées dans le pédoncule cérébelleux chez les cas d'AMS-C par rapport aux témoins et par rapport aux patients atteints de MP et de PSP (p < 0,001). Conclusion : La combinaison d'hypointensité et d'atrophie du putamen à l'ÉG est utile pour différencier l'AMS-P des autres syndromes parkinsoniens.

Can J Neurol Sci. 2013; 40: 389-402

Multiple system atrophy (MSA), Parkinson's disease (PD), progressive supranuclear palsy (PSP) and corticobasal degeneration (CBD) can sometimes be clinically indistinguishable, especially early in the clinical course. However all differ in the pattern of neurodegeneration and cellular damage. ${ }^{1-3}$ Volumetric studies are able to evaluate atrophy in specific areas of the brain..$^{4-7}$ However, these are time consuming and seldom used in clinical practice.

Over the years, based on the pattern of neuronal loss, various radiological signs have been proposed to differentiate parkinsonian disorders. ${ }^{8-11}$ While some may be specific they lack sensitivity and others though sensitive are seen in patients with various parkinsonian syndromes. A magnetic resonance imaging

From the Movement Disorders Center and the Edmond J. Safra Program in Parkinson's Disease, Division of Neurology (PMW, JR, AA, AEL), Department of Medical Imaging (PH, MQR, DJM), Toronto Western Hospital, University Health Network, University of Toronto, Canada; Department of Neurology (PMW), Jaslok Hospital and Research Institute, Mumbai, India.

Received March 20, 2012. Final Revisions Submitted December 11, 2012. Correspondence to: Anthony E. Lang, 399 Bathurst Street, MC-7-402, Toronto Western Hospital, Toronto, Ontario, M5T 2S8, Canada. 
(MRI) rating scale for the diagnosis of the parkinsonian form of MSA (MSA-P) and PSP has been recently proposed, however the diagnostic sensitivity and specificity has not yet been assessed. $^{12}$

Recently, gradient echo (GRE) $)^{13,14}$ and diffusion weighted imaging (DWI) ${ }^{15-21}$ have held a new promise for differentiating these disorders. Diffusion weighted imaging reflects the constrained movement of water molecules associated with myelinated fiber tracts in the normal brain (water molecules move freely along the tracts with restricted movement perpendicular to the fiber tracts), the so-called anisotropy of diffusion. ${ }^{22}$ Pathological processes that modify tissue architectural integrity, including neuronal loss and secondary astrogliosis, remove some of the restrictions to water molecule movement, thereby increasing water diffusion and increasing the apparent diffusion coefficient (ADC). Thus, depending on the distribution of neurodegeneration, ADC measurements in different regions of the brain may help in differentiating the neurodegenerative disorders. Higher ADC values have been reported in the putamen in patients with MSA-P and in the middle cerebellar peduncle in patients with the cerebellar form of MSA (MSA-C) compared to patients with PD. ${ }^{15,17,20,21,23}$ Deposition of paramagnetic substances like iron is associated with a reduction of the $\mathrm{T} 2 *$ relaxation time producing a hypointense signal on GRE (T2*) imaging. ${ }^{13,14,24}$ Histopathological studies in patients with MSA demonstrate iron deposition in the putamen. ${ }^{25}$ Recently, T2 hypointensity in the putamen has been shown to correlate with ferritin deposition in the putamen on post-mortem studies. ${ }^{26}$ Hypointensity of the putamen (compared to the pallidum) on GRE imaging has been demonstrated in patients with MSA-P versus those with PD..$^{13,14}$ However, there has been a paucity of studies comparing GRE imaging in patients with MSA-P versus PD and other parkinsonian syndromes. Gradient echo and DWI have never been compared simultaneously in different parkinsonian syndromes.

We evaluated the sensitivity and specificity of a variety of radiological signs in differentiating parkinsonian syndromes using conventional MRI, GRE and DWI sequences in patients with MSA, PSP and corticobasal syndrome (CBS) compared to patients with PD and controls.

\section{Methods}

\section{Patient selection}

Patients attending the Movement Disorders Clinic at the Toronto Western Hospital and classified as having parkinsonism, PD, MSA, PSP, or CBS/CBD who had undergone MRI of the brain at the University Health Network (UHN) hospitals in Toronto, Canada from May 2002 to February 2008 were included in the study. GRE has been part of the standard MR protocol at UHN since May 2002. Controls had a normal MRI of the brain during investigations for other neurological indications over the same period.

Charts of the patients were reviewed (by JR and PW) and clinical data was extracted from clinic visits closest to the date of the MRI. In cases where more than one MRI scan was available, the first and last MRI were included for analysis and corresponding visit notes were analyzed. Standard diagnostic criteria were applied (Appendix). ${ }^{27-31}$ Some of the diagnostic criteria were modified at the outset to include patients with earlier presentations of the disease. In addition to the previously described criteria, we included patients with slowing of downward saccades, abnormalities of vertical OKN and the presence of postural instability within the first year for the diagnosis of PSP without mandating the presence of falls. ${ }^{28,29}$ As recommended by the Movement Disorder Society Scientific Issues Committee committee ${ }^{29}$ we added a set of less rigid criteria in the diagnostic profile of MSA. ${ }^{30}$ In the diagnostic criteria for CBS we dropped dementia from the exclusion criteria, recognising that patients with a clinical presentation of dementia are often found to have corticobasal degeneration on histopathology. ${ }^{27}$ For the diagnosis of PD we used the UKPDS Brain Bank criteria, removing the presence of a positive family history from the exclusion criteria. ${ }^{31}$ The clinical data was entered into an Excel database that automatically computed the clinical criteria, determining if the diagnosis was fulfilled for any of the parkinsonian syndromes. The expert diagnosis by the movement disorder specialist at the time of the clinic visit was also recorded. In patients with more than one MRI scan the clinical diagnosis at the visit corresponding to the last visit was recorded as the final diagnosis. Patients not fitting the clinical diagnostic criteria for any of the four parkinsonian syndromes were labelled as undiagnosed for the purpose of the study.

\section{MRI protocol}

Imaging was performed on $1.5 \mathrm{~T}$ or $3 \mathrm{~T}$ MRI systems (HD platforms GE Healthcare Milwaukee) using eight channel head coils following a uniform MRI protocol (supplementary data).

\section{Image analysis}

We excluded patients with major deviations in the protocol where more than one sequence was missing including the GRE sequence (typically when $\mathrm{T}_{2}$ axial + GRE or ADC + GRE were missing). We included patients where one sequence was missing, but excluded them from any analysis that required the missing sequence. Peri-operative MRI's (e.g., from deep brain stimulation in PD) were excluded from the analysis to prevent unblinding of the raters. While we included patients with both 1.5T and 3T MRI scans who fit criteria, there were only four patients with 3T MRIs who fulfilled criteria, (2 PSP, 1 PD and 1 MSA-P).

Two blinded independent raters (PH and MQ) evaluated the MRI scans for all qualitative data (conventional $\mathrm{T}_{1}$ and $\mathrm{T}_{2}$ sequence signs (see below) and GRE hypointensity), using standard templates for each sign using examples published in the literature. The raters were blinded to the clinical data of patients and controls. Inter- and intra-rater reliability was also assessed for each of the signs randomly in a select number of patients (inter-rater: 31 scans, intra-rater: 14 scans). Pontine anteroposterior (A-P) diameter measurements and ADC measurements were performed by one unblinded rater (PW).

Putamen atrophy, slit like hyperintensity and the presence of a hot cross bun sign were rated as present unequivocally or not on $\mathrm{T}_{2}$ axial sequences compared to standard templates. Hypointensity of the putamen on $\mathrm{T}_{2}$ axial sequences was defined as intensity of the putamen equal to or lower than the intensity of the pallidum excluding regional signal loss in the posterior and lateral parts of the putamen; with or without a band of 
hyperintensity within the putamen. ${ }^{32,33}$ The presence of a "Hummingbird sign" was accepted if present unequivocally on $\mathrm{T}_{1}$ mid-sagittal images. ${ }^{34}$ The "morning glory sign" was rated as present based on clear evidence of concavity of the lateral margin of the midbrain tegmentum as reported previously. ${ }^{8}$ Hyperintensity of the middle cerebellar peduncles (MCP) was accepted if unequivocally present on $\mathrm{T}_{2}$ axial sequences at the thickest point along a line perpendicular to the MCP at the level of the internal auditory meatus or facial nerve. ${ }^{15}$ Pontine A-P diameter was measured on $\mathrm{T}_{1}$ mid-sagittal images by measuring the largest A-P diameter of the pons perpendicular to the fourth ventricle. ${ }^{35}$

Gradient echo scans were rated using criteria described previously. ${ }^{13}$ We considered the sign to be present when the putamen was hypointense compared to the pallidum (grades 2, and 3$)^{13}$. Subsequently those with GRE hypointensity were blindly rated post-hoc (by DJM, AEL) to evaluate the presence of both atrophy (on $\mathrm{T}_{2}$ and GRE) and GRE hypointensity.

For the measurement of ADC values, elliptical regions of interest (ROIs) were manually placed bilaterally in the MCPs, putamen and lateral ventricles using the axial $\mathrm{T}_{2}$-weighted images as guidance. The MCPs were measured at their thickest point along the line perpendicular to the MCP at the level of the internal auditory meatus and facial nerve. ${ }^{15}$ The putamen was measured with elliptical ROIs, which were completely within the putamen (supplementary Figure 1).

The study was approved by the research ethics board at the University Health Network. Comparisons across the study groups were performed using a series of chi-square tests, GLM tests, and t-tests unless otherwise specified. Post hoc comparisons were made using the Tukey's test for quantitative data and Bonferonni adjusted pairwise comparisons for categorical data. Sensitivity and specificity for regional ADC (rADC) and pontine A-P diameter measurements was calculated using optimal cut-off values determined by receiver operating characteristics (ROC) curve analysis. For inter-rater and intrarater reliability analysis a kappa value of 0.4-.59 suggested moderate agreement, 0.6-0.79 substantial agreement and 0.8-1.0 outstanding agreement. ${ }^{36}$

\section{RESULTS}

A total of 131 patients with parkinsonism scanned from May 2002 to February 2008 and 64 controls (see supplementary data for distribution) were included for the purpose of the study (Table 1). In patients with more than one MRI we included the MRI at the last visit and the corresponding clinical assessment for the analysis.

Due to the heterogeneous nature of the population with parkinsonism it was not possible to have controls age and sex matched for all diseases. Our controls, like the patients with MSA were younger and more likely to be female, compared to an older predominantly male population with PSP and PD. As expected, patients with PD had the longest disease duration and lower Hoehn and Yahr scores compared to those with atypical parkinsonian syndromes (Table 1).

\section{Conventional $T_{1}$ and $T_{2}$ signs}

Among the signs on T2-weighted MRI studying structural changes in the basal ganglia (Supplementary Table 1, Figure 1, a-d), atrophy of the putamen was seen more commonly in patients with MSA-P and PSP compared to patients with PD and controls. Putamen hypointensity was more common in patients with MSA-P compared to controls and patients with PD and PSP. Slit-like hyperintensity in the putamen was significantly more common in patients with MSA-P compared to those with PSP, PD and controls. Atrophy of the putamen alone lacked specificity for the diagnosis of MSA-P (Table 2). Putamen

\section{Table 1: Demographic information and disease severity}

\begin{tabular}{|c|c|c|c|c|c|c|c|c|c|}
\hline Variable & CBS & MSA-C & MSA-P & PD & PSP & Undiagnosed & Controls & Total & Significance \\
\hline Total N & $6(3.1 \%)$ & $\begin{array}{c}7^{\mathrm{a}} \\
(3.6 \%)\end{array}$ & $15(7.7 \%)$ & $\begin{array}{c}61 \\
(31.3 \%) \\
\end{array}$ & $21(10.8 \%)$ & $21(10.8 \%)$ & $64(32.8 \%)$ & 195 & \\
\hline Mean age at MRI & $69.2+/-7.9$ & $61.4+/-7.6$ & $\begin{array}{l}65.5+/- \\
12.4\end{array}$ & $\begin{array}{c}65.8+/- \\
10.6\end{array}$ & $68+/-8.4$ & $69.7+/-7.8$ & $57.3+/-11.3$ & & $\mathrm{p}<0.001$ \\
\hline Males n (\%) & $3(50)$ & $\begin{array}{c}2 \\
(28.6) \\
\end{array}$ & $8(53.3)$ & $41(67.2)$ & $17(81)$ & $13(61.9)$ & $23(35.9)$ & $\begin{array}{c}107 \\
(54.9)\end{array}$ & $\mathrm{p}=0.001$ \\
\hline $\begin{array}{l}\text { Mean Disease } \\
\text { duration (mths) }\end{array}$ & $\begin{array}{c}48.8+/- \\
40.7 \\
\end{array}$ & $\begin{array}{c}36.3+/- \\
22.0\end{array}$ & $\begin{array}{c}46.3+/- \\
17.0\end{array}$ & $\begin{array}{c}84.3+/- \\
63.8 \\
\end{array}$ & $\begin{array}{c}55.4+/- \\
50.2\end{array}$ & $54.55+/-38.3$ & N/A & $\begin{array}{c}63.3+/- \\
(52.7) \\
\end{array}$ & $\mathrm{p}=0.012$ \\
\hline $\begin{array}{l}\text { Median disease } \\
\text { duration (mths) }\end{array}$ & 37 & 31 & 45 & 70 & 39 & 54 & N/A & & \\
\hline $\begin{array}{l}\text { Mean H \& Y } \\
\text { score }\end{array}$ & $\begin{array}{c}3.6+/-1.7 \\
(\mathrm{~N}=4)\end{array}$ & $\begin{array}{c}4.0+/-0.7 \\
(\mathrm{~N}=5)\end{array}$ & $\begin{array}{c}3.5+/-1.0 \\
(\mathrm{~N}=15)\end{array}$ & $\begin{array}{c}2.6+/-0.9 \\
(\mathrm{~N}=57)\end{array}$ & $\begin{array}{c}3.7+/-0.9 \\
(\mathrm{~N}=19)\end{array}$ & $\begin{array}{c}2.6+/-1.0 \\
(\mathrm{~N}=15)\end{array}$ & N/A & $(\mathrm{N}=115)$ & $\mathrm{p}<0.001$ \\
\hline
\end{tabular}

CBS = Corticobasal syndrome, MSA-C = Multiple system atrophy cerebellar type, MSA-P = Multiple system atrophy parkinsonian type, $\mathrm{PD}=$ Parkinson's disease, PSP = Progressive supranuclear palsy, H \& Y = Hoehn and Yahr. Controls were significantly younger than patients with PSP $(p=0.001)$ and PD $(p<0.0001)$. Controls were more likely to be female as compared to patients with PSP ( $p=0.003)$ and PD ( $=0.0005)$. Patients with PD had lower H \& Y scores compared to patients with MSA-P ( $\mathrm{p}=0.0004)$, MSA-C ( $\mathrm{p}=0.0034)$ and PSP ( $<<0.0001)$. ${ }^{\mathrm{a} .5 / 7}$ had additional parkinsonism,1/7 had only bradykinesia, but none of the other features, $1 / 7$ had pure cerebellar ataxia with no parkinsonian signs. 
Table 2: Sensitivity and specificity of different radiological signs

\begin{tabular}{|c|c|c|c|c|c|c|}
\hline Sign & $\begin{array}{l}\text { Disease for which } \\
\text { sensitivity assessed }\end{array}$ & Sensitivity & $\begin{array}{c}\text { Specificity } \\
\text { compared to PD }\end{array}$ & $\begin{array}{c}\text { Specificity } \\
\text { compared to PSP }\end{array}$ & $\begin{array}{l}\text { Specificity compared } \\
\text { to controls }\end{array}$ & $\begin{array}{c}\text { Specificity } \\
\text { compared to MSA }\end{array}$ \\
\hline Atrophy of putamen on $T_{2}$ & MSA-P & 73.3 & 73.8 & 47.6 & 93.8 & NA \\
\hline $\mathrm{T}_{2}$ Hypointensity of Putamen & MSA-P & 40.0 & 90.2 & 90.5 & 96.9 & NA \\
\hline $\begin{array}{c}\mathrm{T}_{2} \text { Slit-like hyperintensity of } \\
\text { putamen }\end{array}$ & MSA-P & 60.0 & 93.4 & 85.7 & 95.3 & NA \\
\hline $\begin{array}{c}\text { GRE Hypointensity of } \\
\text { putamen }\end{array}$ & MSA-P & 73.3 & 90.0 & 76.2 & 93.7 & NA \\
\hline $\begin{array}{l}\text { GRE hypointensity + atrophy } \\
\left(\text { GRE and } \mathrm{T}_{2}\right) \text { of putamen }\end{array}$ & MSA-P & 73.3 & 98.3 & 95.2 & 100 & NA \\
\hline $\begin{array}{l}\text { rADC value of putamen } \\
\geq 0.840 \times 10^{-3} \mathrm{~mm}^{2} / \mathrm{sec}^{\mathrm{a}}\end{array}$ & MSA-P & 33.3 & 73.7 & 61.9 & 87.5 & NA \\
\hline Hot cross bun sign & MSA-C & 71.4 & 100 & 90.5 & 100 & NA \\
\hline Hyperintensity of MCP & MSA-C & 42.9 & 100 & 100 & 100 & NA \\
\hline $\begin{array}{l}\text { Pontine AP diameter below } \\
\qquad 21 \mathrm{~mm}^{\mathrm{a}}\end{array}$ & MSA-C & 71.4 & 98.4 & 90.5 & 98.4 & NA \\
\hline $\begin{array}{c}\text { rADC value of MCP } \geq 0.940 \\
\times 10^{-3} \mathrm{~mm}^{2} / \mathrm{sec}^{\mathrm{a}}\end{array}$ & MSA-C & 66.7 & 91.4 & 100 & 87.5 & NA \\
\hline Hummingbird sign & PSP & 47.6 & 91.8 & NA & 100 & 86.4 \\
\hline Morning glory sign & PSP & 9.5 & 100 & NA & 100 & 100.0 \\
\hline
\end{tabular}

$\mathrm{rADC}=$ regional apparent diffusion coefficient, GRE= Gradient echo imaging, MSA-C = Multiple system atrophy cerebellar type, MSA-P = Multiple system atrophy parkinsonian type, $\mathrm{PSP}=$ Progressive supranuclear palsy, $\mathrm{MCP}=$ Middle cerebellar peduncle. ${ }^{\text {a }}$ Cut off values calculated using ROC curves to try and achieve the best specificity and sensitivity for that value.

hypointensity on $\mathrm{T}_{2}$ sequences on the other hand was specific, but lacked sensitivity in detecting MSA-P. Slit-like hyperintensity was seen in $60 \%$ of the patients with MSA-P with a good specificity (Table 2).

We assessed two signs of changes in midbrain anatomy (Supplementary Table 1, Figure 1, e-h), namely the presence of the "hummingbird sign" 34 and concavity of the midbrain tegmentum, the "morning glory sign" 8 . The Hummingbird sign was more common in patients with PSP as compared to controls and those with PD, but not MSA-P. The morning glory sign was very rare; only two patients with PSP and one patient who did not fit criteria for PSP at the time of assessment (but had a clinical syndrome compatible with PSP) had concavity of the midbrain tegmentum. While both signs seem highly specific for the diagnosis of PSP, they both lack sensitivity with hummingbird sign present in less than $50 \%$ and the morning glory sign in less than $10 \%$ of the clinically diagnosed cases of PSP (Table 2).

Among signs assessing pontine and cerebellar anatomy, the presence of the hot cross bun sign and hyperintensity of the MCP were significantly more common in patients with MSA-C compared to controls, patients with PD and PSP. The mean pontine A-P diameter was significantly lower in patients with MSA-C compared to controls and patients with PD, PSP and CBS (Supplementary Table 1, Figure $1 \mathrm{k}-1$ ). Both the hot cross bun sign and a low pontine A-P diameter (Figure $1 \mathrm{i}-\mathrm{j}$ ) were sensitive for the diagnosis of MSA-C (Table 2). While these signs were specific when compared to patients with other parkinsonian syndromes, we did not have patients with other degenerative or genetic ataxias for comparison making interpretation of specificity difficult.

At least moderate agreement was obtained in all signs among the two raters and also within the same rater (Supplementary Table 2). Inter-rater and intra-rater agreement was less for signs involving putamen anatomy as compared to signs like the hummingbird sign and hot cross bun sign where it is easier to interpret if the sign is present or absent.

\section{GRE scans}

As seen in Table 3,73.3\% of the patients with MSA-P had hypointensity of the putamen on GRE scans compared to the pallidum (MSA-P versus controls $\mathrm{p}<0.0001$, MSA-P versus PD $\mathrm{p}<0.0001$, MSA-P vs PSP $\mathrm{p}=0.042$ ). A post-hoc blinded analysis (by two further reviewers, DJM, AEL) was conducted in all cases with hypointensity of the putamen (compared to the pallidum) rating putamenal atrophy visually using both GRE and $\mathrm{T}_{2}$-weighted axial sequences (Figure 2, Table 3 and brief case reports in Supplementary Information). The combination of putamenal atrophy and GRE hypointensity was significantly more common in patients with MSA-P compared to PD $(\mathrm{p}<0.0001)$, PSP $(\mathrm{p}=0.0006)$, and controls $(\mathrm{p}<0.0001)$. When atrophy and hypointensity were combined, the specificity of GRE images in diagnosing MSA-P was significantly higher than with using hypointensity alone (Table 2). 


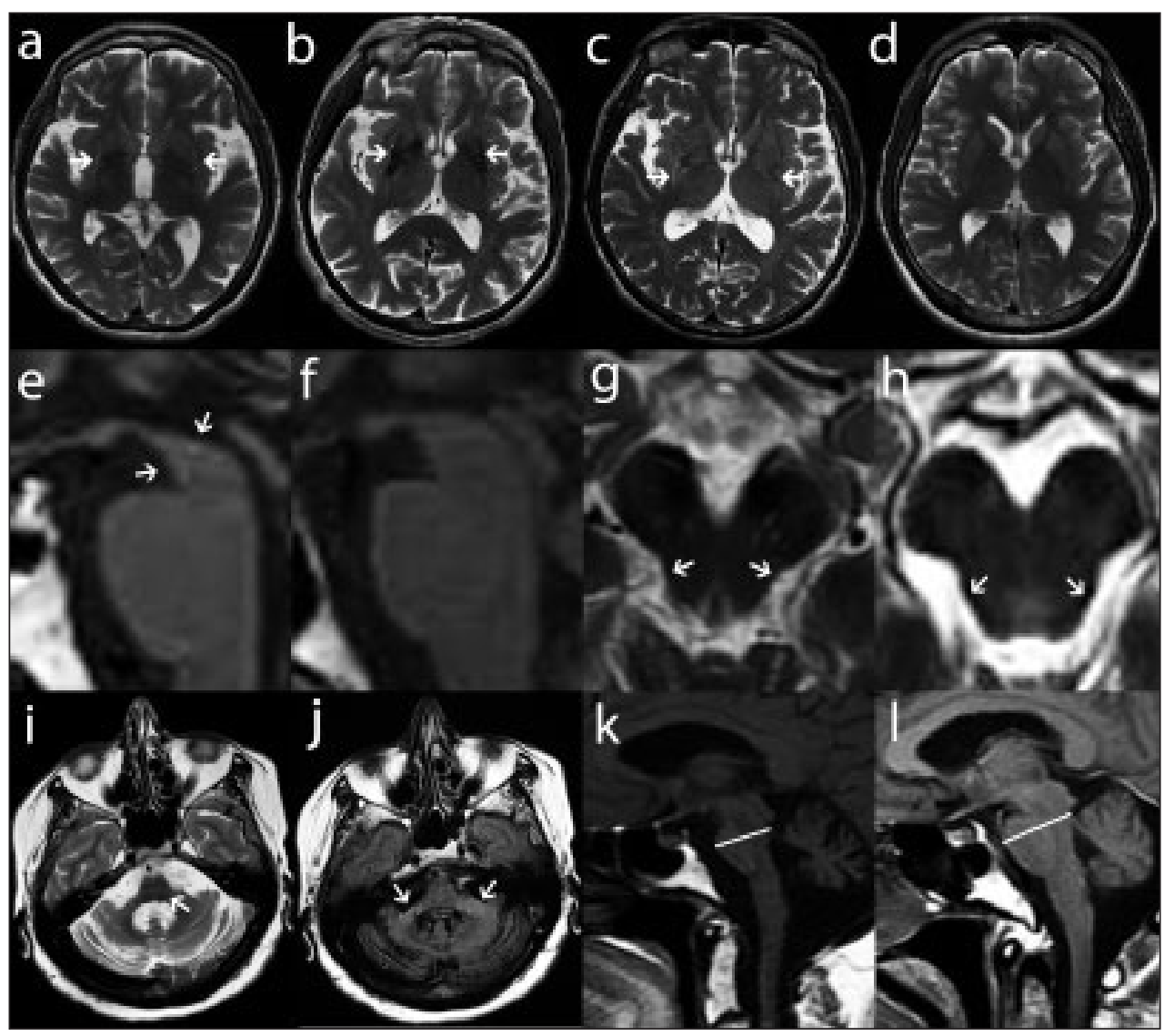

Figure 1: MR Images demonstrating different signs on structural imaging. Images a-d: T2-weighted axial MRI images of the basal ganglia a. Atrophy of the putamen (also see slit hyperintensity), $b$. Hypointensity of the putamen $c$. Slit-like hyperintensity of the putamen $d$. Control MRI (normal). Images e,f: T1-weighted sagittal images showing the hummingbird sign in a patient with PSP (e) compared to a normal control (f). Images $g, h:$ T2-weighted axial images of the midbrain showing tegmental concavity (the morning glory sign) in a patient with PSP ( $g$ ) compared to convexity in a patient with PD (h). Images $i$, T2-weighted and $j$, FLAIR axial MRI images of patients with MSA-C of the pontocerebellar region, showing a hot cross bun sign (i) and hyperintensity of the middle cerebellar peduncle $(j)$. Images $k, l$ : T1-weighted sagittal images showing pontine atrophy in a patient with MSA-C $(k)$ compared to a normal pons in a patient with $P D(l)$.

Antero-posterior gradient of hypointensity in the putamen was seen commonly among patients with both MSA-P and PSP and to a lesser extent among other groups, significantly reducing the specificity of this sign (Table 3 ).

\section{ADC maps}

Comparing rADC (regional ADC) values among the regions of interest (Table 4), patients with MSA-C had significantly higher rADC values in the MCP compared to patients with PD $(\mathrm{p}=0.013)$, PSP $(\mathrm{p}=0.016)$ and controls $(\mathrm{p}=0.014)$. However, rADC values in the putamen in patients with MSA-P were no different from those in patients with PD, PSP or CBS (Table 4).

We plotted ROC curves of the rADC values assigning cut off values for the MCP $\left(0.940 \times 10^{-3} \mathrm{~mm}^{2} / \mathrm{sec}\right)$ and the putamen $\left(0.840 \times 10^{-3} \mathrm{~mm}^{2} / \mathrm{sec}\right)$; using these, rADC assessment in the MCP was specific for the diagnosis of MSA-C compared to the other parkinsonian groups, but lacked sensitivity (Table 2).

Table 3: Comparison of the intensity on gradient echo imaging

\begin{tabular}{|c|c|c|c|c|c|c|c|c|}
\hline Characteristic & CBS & Control & MSA-C & MSA-P & PD & PSP & Undiagnosed & Significance \\
\hline Total No of cases & 6 & 64 & 7 & 15 & $60^{\mathrm{a}}$ & 21 & 21 & \\
\hline $\begin{array}{l}\text { Hypointensity of the putamen on GRE } \\
\text { (compared to pallidum) }\end{array}$ & $1(16.7)$ & $4(6.3)$ & $1(14.3)$ & $11(73.3)$ & $6(10.0)$ & $5(23.8)$ & $5(23.8)$ & $\mathrm{p}<0.0001$ \\
\hline $\begin{array}{c}\left.\text { Putamen atrophy (GRE and } \mathrm{T}_{2}\right)+ \text { hypointensity } \\
\text { on GRE (compared to pallidum) }\end{array}$ & 0 & 0 & $1(14.3)$ & $11(73.3)$ & $1(1.7)$ & $1(4.8)$ & 0 & $\mathrm{p}<0.0001$ \\
\hline $\begin{array}{l}\text { Presence of a rostro caudal gradient of } \\
\text { hypointensity (GRE) in the putamen }\end{array}$ & $2(33.3)$ & $\begin{array}{c}17 \\
(26.6)\end{array}$ & $3(42.9)$ & $13(86.7)$ & $20(32.8)$ & $14(66.7)$ & $13(61.9)$ & $\mathrm{p}=0.0005$ \\
\hline
\end{tabular}

GRE = gradient echo sequence, $\mathrm{CBS}=$ Corticobasal syndrome, MSA-C = Multiple system atrophy cerebellar type, MSA-P = Multiple system atrophy parkinsonian type, $\mathrm{PD}=$ Parkinson's disease, $\mathrm{PSP}=$ Progressive supranuclear palsy. ${ }^{\mathrm{a}} 1$ patient with PD did not have a gradient echo sequence (denominator for $\mathrm{PD}=60$ ). Numbers in parentheses are percentages. 
Table 4: Comparison of ADC values in the putamen, middle cerebral peduncle and CSF

\begin{tabular}{|c|c|c|c|c|c|c|c|c|}
\hline rADC value ${ }^{a}$ & CBS & Controls & MSA-C & MSA-P & PD & PSP & Undiagnosed & Significance \\
\hline $\mathrm{N}^{\mathrm{b}}$ & 5 & 64 & 6 & 15 & 57 & 21 & 21 & \\
\hline MCP (right) & $0.86+/-0.16$ & $0.75+/-0.13$ & $0.95+/-0.10$ & $0.83+/-0.12$ & $0.72+/-0.13$ & $0.71+/-0.10$ & $0.70+/-0.10$ & $<0.0001$ \\
\hline MCP (left) & $0.84+/-0.13$ & $0.75+/-0.15$ & $0.90+/-0.13$ & $0.78+/-0.12$ & $0.71+/-0.12$ & $0.72+/-0.10$ & $0.74+/-0.09$ & 0.0054 \\
\hline MCP (mean) & $0.85+/-0.15$ & $0.75+/-0.13$ & $0.93+/-0.11$ & $0.80-+/-0.10$ & $0.69+/-0.17$ & $0.71+/-0.09$ & $0.72+/-0.08$ & 0.0339 \\
\hline Putamen (right) & $0.86+/-0.13$ & $0.72+/-0.10$ & $0.73+/-0.09$ & $0.81+/-0.15$ & $0.80+/-0.09$ & $0.80+/-0.09$ & $0.79+/-0.14$ & 0.0069 \\
\hline Putamen (left) & $0.87+/-0.12$ & $0.75+/-0.09$ & $0.80+/-0.14$ & $0.88+/-0.20$ & $0.84+/-0.16$ & $0.84+/-0.09$ & $0.81+/-0.13$ & 0.0023 \\
\hline Putamen (mean) & $0.86+/-0.11$ & $0.73+/-0.09$ & $0.76+/-0.13$ & $0.85+/-0.17$ & $0.79+/-0.215$ & $0.82+/-0.08$ & $0.80+/-0.12$ & 0.0184 \\
\hline CSF (right) & $3.51+/-0.27$ & $3.35+/-0.34$ & $3.41+/-0.33$ & $3.37+/-0.29$ & $3.41+/-0.28$ & $3.36+/-0.26$ & $3.03+/-0.93$ & 0.0336 \\
\hline CSF (left) & $3.65+/-0.21$ & $3.49+/-0.29$ & $3.54+/-0.37$ & $3.40+/-0.28$ & $3.44+/-0.26$ & $3.51+/-0.32$ & $3.47+/-0.28$ & 0.6550 \\
\hline
\end{tabular}

${ }^{\mathrm{a}} \mathrm{rADC}$ values $\left(\mathrm{x} 10^{-3} \mathrm{~mm}^{2} / \mathrm{sec}\right)$ are reported as mean $+/$ - standard deviation. ${ }^{\mathrm{b}}$ Not all patients had ADC sequences. Denominators reflect only those with $\mathrm{ADC}$ sequences. $\mathrm{rADC}=$ regional apparent diffusion coefficient, $\mathrm{CBS}=$ Corticobasal syndrome, MSA-C = Multiple system atrophy cerebellar type, MSA-P = Multiple system atrophy parkinsonian type, $\mathrm{PD}=$ Parkinson's disease, $\mathrm{PSP}=$ Progressive supranuclear palsy, $\mathrm{MCP}=\mathrm{Middle}$ cerebellar peduncle, $\mathrm{CSF}=$ cerebrospinal fluid.

\section{Predictive role of imaging in early and undiagnosed cases}

Four of six cases fulfilling the criteria of MSA-P at the final visit but not at the first clinical visit (mean duration between visits was 20.5 months) had GRE hypointensity and atrophy of the putamen at the time when the clinical criteria for MSA-P were not met. The remaining two patients not showing GRE hypointensity at the first visit continued to have normal scans 20 months later. On the other hand only one of four cases having serial imaging and fulfilling criteria for MSA-P at all time points showed GRE hypointensity and atrophy on the second MRI scan not present in the first.

There were 21 cases in our study that did not fulfill our diagnostic criteria for the parkinsonian syndromes at their last visit (Supplementary Table 3). Four cases showed MRI signs that are seen in patients with MSA. All had a clinical syndrome which could be compatible with MSA, though they did not fulfill the prespecified clinical criteria. Two of the patients with postural instability and gait problems showed MRI signs seen in PSP, both had a clinical picture suggestive of PSP (supplementary Table 3).

\section{Discussion}

\section{Standard T1/T2 MRI signs}

Several studies have evaluated different signs on standard $\mathrm{T}_{2}$ weighted MRI. Among signs evaluating patients with MSA-P, hypointenstiy of the putamen or a linear slit like hyperintensity of the putamen have been most commonly used..$^{10,11,32,33,37-41}$

Putamen atrophy has been evaluated accurately using volumetric MRI, however this is extremely time consuming and difficult to put into clinical practice. ${ }^{7}$ Studies evaluating the presence of putamen atrophy in MSA based on a visual rating have found the prevalence to be highly variable from 31$100 \% .{ }^{11,18,33,39,42}$ Using templates from previous studies, we found a lack of specificity for the diagnosis of MSA-P, especially when compared to PSP (Table 2). ${ }^{11}$
Hypointensity of the putamen on $\mathrm{T}_{2}$-weighted imaging has been reported in 40-90\% of MSA cases depending on patient selection (MSA-P alone or all cases with MSA) and the definition used (eg. signal intensity compared to pallidum). ${ }^{10,11,32,33,37-41}$ Most of these studies reported relatively good specificity when comparing MSA to PD. The few studies that included patients with PSP, showed a lowered specificity when compared to PSP, contrary to our study. It is possible that the use of templates of putamen hypointensity on $\mathrm{T}_{2}$-weighted MRI, as in our study could have been responsible in improving the specificity in diagnosing MSA-P, but at the same time having a lower sensitivity.

Linear slit-like hyperintensity of the putamen was found in $60 \%$ of our MSA cases compared to $26-83 \%$ in the literature. ${ }^{10,11,14,18,32,33,38,39,43,44}$ In our study, largely using $1.5 \mathrm{~T}$ scans (only 4/195 had 3T), this sign had good specificity compared to both PD and MSA (Table 2). While this sign may be useful as a diagnostic tool for MRI's done on 1.5T MRI machines, we have often seen a long linear rim on the lateral margin of the putamen on T2-weighted scans done on a 3T scanner in patients with various diagnoses and a study of healthy adults showed significant false positive hyperintense putamen rims on $3 \mathrm{~T}$ compared to $1.5 \mathrm{~T}$ MRI scans.${ }^{45}$ Recently an increase in the MRI field strength resulted in a decrease in the occurrence of hyperintensity both at the dorsolateral outer putaminal margin and an increase in the occurrence of hypointensity at the dorsolateral putaminal margin in patients with MSA. ${ }^{46}$

The hot-cross bun sign was present in $71 \%$ of patients with MSA-C in our study compared to $50-80 \%$ of the patients with MSA-C, or MSA in the literature..$^{39,44,47}$ It has been proposed that this sign is due to selective loss of myelinated transverse pontocerebellar fibers and neurons in the pontine raphe with preservation of the pontine tegmentum and corticospinal tracts ${ }^{48}$ as well as gliosis of the middle part of the pontine reticular formation, and the pontocerebellar fibers. ${ }^{49}$ While there was a good specificity for this sign in our study population, we did not 


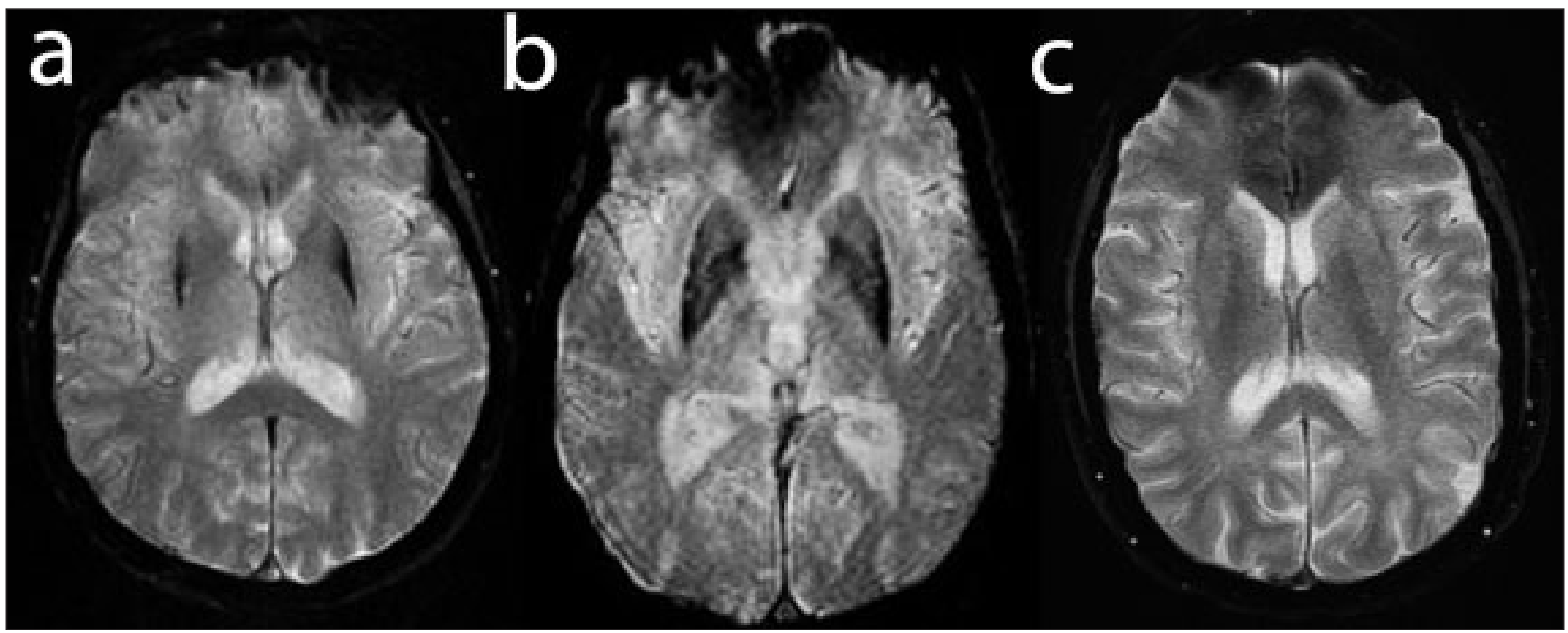

Figure 2: Gradient Echo Imaging in parkinsonism. A patient with MSA-P showing both atrophy and hypointensity of the putamen bilaterally (a), a patient with PSP showing hypointensity of the putamen without atrophy (b), a patient with PD with a normal putamen on the GRE sequence (c).

include patients with spinocerebellar ataxias where the hot cross bun sign has also been reported..$^{50,51}$

We found hyperintensity of the MCP in $43 \%$ of the patients with MSA-C; this has been reported in $21-50 \%$ of patients with MSA, ${ }^{33,38,44}$ higher in studies looking only at MSA-C. ${ }^{38}$ While the specificity of this sign was found to be good when compared to patients with parkinsonism in our study, this sign has been reported in $14 \%$ of MRIs done for tinnitus or hearing $\operatorname{loss}^{52}$ and it has also been reported in spinocerebellar ataxias, adrenoleukodystrophy, HIV encephalopathy and Fragile X tremor ataxia syndrome..$^{53,54}$

Pontine A-P diameter ${ }^{35,55}$ below $21 \mathrm{~mm}$ had a good sensitivity and specificity for MSA-C but did not differentiate other forms of parkinsonism.

The hummingbird sign was less sensitive ${ }^{56}$ and the morning glory $\operatorname{sign}^{8}$ was distinctly uncommon, suggesting that it is a late sign that is of little use in the early differentiation of parkinsonian disorders. However both were specific for the diagnosis of PSP.

\section{GRE signs}

The sensitivity and specificity profile of GRE sequences in differentiating MSA from PD was similar to previous reports (35-69\% and $88-89 \%) \cdot{ }^{13,14,57,58}$ It has been suggested that the specificity for MSA could be improved if this sign were combined with a slit like $\mathrm{T}_{2}$ weighted hyperintensity of the putamen. ${ }^{14}$ Two studies evaluating putaminal hypointensity using GRE or susceptibility-weighted imaging (SWI) sequences in MSA-P included patients with PSP in their study. ${ }^{59,60}$ As in these studies, we found hypointensity of the putamen in some of the patients with PSP, significantly reducing the specificity of the sign (Table 2, 3). However, we were impressed by the differences in the morphology with atrophy of the putamen in MSA-P (Figure 2) compared to those in PSP. Blinded post-hoc analysis confirmed the presence of the combination of putamenal atrophy ( $\mathrm{T}_{2}$ and GRE) and GRE hypointensity (Table 3 ) with moderately good sensitivity (73\%) and excellent specificity for the diagnosis of MSA-P compared with PD (specificity 98.3\%), PSP (specificity 95.2\%) and controls (specificity 100\%).

This sign was also present in four out of six patients with MSA-P, prior to fulfilling clinical criteria, indicating that it may be a useful sign for the diagnosis of MSA-P in the early stages of the disease.

\section{ADC maps}

Most studies measuring rADC values in the putamen found a higher ADC value in patients with MSA-P as compared to PD and controls. ${ }^{16,18,20,23,43,61}$ When rADC values of the putamen of MSA-P and PSP were compared the results have been mixed; showing no significant difference,,${ }^{17,23}$ or a lower specificity. ${ }^{16}$ As in at least one previous study, ${ }^{17}$ we did not find higher rADC values in the putamen in patients with MSA-P. Methodological differences in slice thickness $(5 \mathrm{~mm}$ compared to $2 \mathrm{~mm}$ in other studies) and ROI measurement (we used only a part of the putamen that included the anterior portion for analysis compared to the entire putamen or exclusively the posterior portion) make it difficult to compare the results of our retrospective evaluation with other prospective studies.

However, despite these methodological differences, we were able to reproduce the higher ADC values in the MCP in patients with MSA-C as compared to other parkinsonian syndromes reported earlier ${ }^{16,17,61,62}$ While this sign is useful when comparing patients with other parkinsonian syndromes, we did not evaluate patients with other cerebellar disorders. Higher ADC values have been described in patients with DRPLA in all cerebellar peduncles, but not in patients with late cerebellar cortical atrophy. ${ }^{63}$ 


\section{Limitations of the study}

Our study suffers from certain limitations. Though we tried to match the controls by age and sex it was not possible to do so for all the diseases due to the heterogeneous nature of the disorders. Most of the signs in our study however, pertained to patients with MSA where the controls were age and sex matched. Due to the retrospective nature of our study we were unable to use high resolution multidirectional DWI protocols applied in prospective trials studying diffusivity in patients in parkinsonian syndromes. ${ }^{18,20,23}$ The methods of measuring ROI's were also different. These differences make it more difficult to compare our results with those from other centers, but show that DWI using routine screening MRI protocols did not adequately differentiate MSA from other disorders. Most of the scans were acquired on 1.5T MRI scanners. A prospective study using three Tesla scans would have provided a better assessment of imaging capabilities now available in most neurosciences centers. However, our study does provide useful and practical data for scans still utilized in many neurological practices. Newer comparative analyses (e.g., midbrain to pontine diameters ${ }^{64}$, diffusion tensor imaging ${ }^{65}$ also need to be evaluated in similar large populations to assess their sensitivity and specificity in the diagnosis of various parkinsonian disorders. We used established clinical criteria. However in the absence of pathological confirmation, misdiagnosis in some of these cases cannot be excluded.

\section{Conclusions}

Hypointensity of the putamen on GRE is extremely valuable especially when combined with atrophy of the putamen in differentiating MSA-P from other forms of parkinsonism. This sign is quick, easy to interpret and can be assessed retrospectively on routine MRI studies.

Our ADC sequence evaluation failed to show useful changes in the striatum in MSA-P. Perhaps not surprisingly, ADC and $\mathrm{T}_{2}{ }^{-}$ weighted abnormalities in posterior fossa structures found in MSA-C differentiated this disorder from other forms of parkinsonism but further studies need to compare this to other degenerative and genetic cerebellar disorders. The hummingbird and morning glory signs, though not sensitive, were fairly specific for the presence of PSP.

\section{ACKNOWLEDGMENT}

Special thanks to William Reginold for help in preparing the figures.

\section{REFERENCES}

1. Hauw JJ, Daniel SE, Dickson D, et al. Preliminary NINDS neuropathologic criteria for Steele-Richardson-Olszewski syndrome (progressive supranuclear palsy). Neurology. 1994;44: 2015-19.

2. Wenning GK, Tison F, Elliott L, Quinn NP, Daniel SE. Olivopontocerebellar pathology in multiple system atrophy. Mov Disord. 1996;11:157-62.

3. Braak H, Del Tredici K, Rub U, de Vos RA, Jansen Steur EN, Braak E. Staging of brain pathology related to sporadic Parkinson's disease. Neurobiol Aging. 2003;24:197-211.

4. Oba H, Yagishita A, Terada H, et al. New and reliable MRI diagnosis for progressive supranuclear palsy. Neurology. 2005; 64:2050-5.
5. Paviour DC, Price SL, Stevens JM, Lees AJ, Fox NC. Quantitative MRI measurement of superior cerebellar peduncle in progressive supranuclear palsy. Neurology. 2005;64:675-9.

6. Paviour DC, Price SL, Jahanshahi M, Lees AJ, Fox NC. Longitudinal MRI in progressive supranuclear palsy and multiple system atrophy: rates and regions of atrophy. Brain. 2006;129:1040-9.

7. Schulz JB, Skalej M, Wedekind D, et al. Magnetic resonance imaging-based volumetry differentiates idiopathic Parkinson's syndrome from multiple system atrophy and progressive supranuclear palsy. Ann Neurol. 1999;45:65-74.

8. Adachi M, Kawanami T, Ohshima H, Sugai Y, Hosoya T. Morning glory sign: a particular MR finding in progressive supranuclear palsy. Magn Reson Med Sci. 2004;3:125-32.

9. Ito S, Shirai W, Hattori T. Evaluating posterolateral linearization of the putaminal margin with magnetic resonance imaging to diagnose the Parkinson variant of multiple system atrophy. Mov Disord. 2007;22:578-81.

10. Kraft E, Schwarz J, Trenkwalder C, Vogl T, Pfluger T, Oertel WH. The combination of hypointense and hyperintense signal changes on $\mathrm{T} 2$-weighted magnetic resonance imaging sequences: a specific marker of multiple system atrophy? Arch Neurol. 1999;56:225-8.

11. Yekhlef F, Ballan G, Macia F, Delmer O, Sourgen C, Tison F. Routine MRI for the differential diagnosis of Parkinson's disease, MSA, PSP, and CBD. J Neural Transm. 2003;110: 151-69.

12. Rolland Y, Verin M, Payan CA, et al. A new MRI rating scale for progressive supranuclear palsy and multiple system atrophy: validity and reliability. J Neurol Neurosurg Psychiatry. 2011;82: 1025-32.

13. Kraft E, Trenkwalder C, Auer DP. T2*-weighted MRI differentiates multiple system atrophy from Parkinson's disease. Neurology. 2002;59:1265-7.

14. von Lewinski F, Werner C, Jorn T, Mohr A, Sixel-Doring F, Trenkwalder C. T2(*)-weighted MRI in diagnosis of multiple system atrophy : a practical approach for clinicians. J Neurol. 2007;254:1184-8.

15. Blain CR, Barker GJ, Jarosz JM, et al. Measuring brain stem and cerebellar damage in parkinsonian syndromes using diffusion tensor MRI. Neurology. 2006;67:2199-205.

16. Nicoletti G, Lodi R, Condino F, et al. Apparent diffusion coefficient measurements of the middle cerebellar peduncle differentiate the Parkinson variant of MSA from Parkinson's disease and progressive supranuclear palsy. Brain. 2006;129:2679-87.

17. Paviour DC, Thornton JS, Lees AJ, Jager HR. Diffusion-weighted magnetic resonance imaging differentiates Parkinsonian variant of multiple-system atrophy from progressive supranuclear palsy. Mov Disord. 2007;22:68-74.

18. Schocke MF, Seppi K, Esterhammer R, et al. Diffusion-weighted MRI differentiates the Parkinson variant of multiple system atrophy from PD. Neurology. 2002;58:575-80.

19. Schocke MF, Seppi K, Esterhammer R, et al. Trace of diffusion tensor differentiates the Parkinson variant of multiple system atrophy and Parkinson's disease. Neuroimage. 2004;21:1443-51.

20. Seppi K, Schocke MF, Donnemiller E, et al. Comparison of diffusion-weighted imaging and [123I]IBZM-SPECT for the differentiation of patients with the Parkinson variant of multiple system atrophy from those with Parkinson's disease. Mov Disord. 2004;19:1438-45.

21. Seppi K, Schocke MF, Mair KJ, et al. Progression of putaminal degeneration in multiple system atrophy: a serial diffusion MR study. Neuroimage. 2006;31:240-5.

22. Le Bihan D, Turner R, Douek P, Patronas N. Diffusion MR imaging: clinical applications. AJR Am J Roentgenol. 1992;159: 591-9.

23. Seppi K, Schocke MF, Esterhammer R, et al. Diffusion-weighted imaging discriminates progressive supranuclear palsy from PD, but not from the parkinson variant of multiple system atrophy. Neurology. 2003;60:922-7.

24. Brass S, Chen N, Mukern R, Bakshi R. Magnetic resonance imaging of iron deposition in neurological disorders. Top Magn Resonance Imaging. 2006;17:31-40. 
25. Lang A, Curran T, Bergeron C. Striatonigral degeneration: iron deposition in putamen correlates with the slit-like void signal of magnetic resonance imaging. Can J Neurol Sci. 1994;9:311-18.

26. Matsusue E, Fujii S, Kanasaki Y, et al. Putaminal lesion in multiple system atrophy: postmortem MR-pathological correlations. Neuroradiology. 2008;50:559-67.

27. Boeve BF, Lang AE, Litvan I. Corticobasal degeneration and its relationship to progressive supranulear palsy and frontotemporal dementia. Ann Neurol. 2003;54:S15-19.

28. Litvan I, Agid Y, Calne D, et al. Clinical research criteria for the diagnosis of progressive supranuclear palsy (Steele-RichardsonOlszewski syndrome): report of the NINDS-SPSP international workshop. Neurology. 1996;47:1-9.

29. Litvan I, Bhatia KP, Burn DJ, et al. Movement Disorders Society Scientific Issues Committee report: SIC Task Force appraisal of clinical diagnostic criteria for Parkinsonian disorders. Mov Disord. 2003;18:467-86.

30. Gilman S, Low PA, Quinn N, et al. Consensus statement on the diagnosis of multiple system atrophy. J Neurol Sci. 1999;163: 94-8.

31. Hughes A, Daniel S, Kilford L, Lees AJ. Accuracy of clinical diagnosis of idiopathic Parkinson's disease: a clinicopathological study of 100 cases. J Neurol Neurosurg Psychiatry. 1992:55:181-4

32. Righini A, Antonini A, Ferrarini M, et al. Thin section MR study of the basal ganglia in the differential diagnosis between striatonigral degeneration and Parkinson disease. J Comput Assist Tomogr. 2002;26:266-71.

33. Bhattacharya K, Saadia D, Eisenkraft B, et al. Brain magnetic resonance imaging in multiple-system atrophy and Parkinson disease: a diagnostic algorithm. Arch Neurol. 2002;59:835-42.

34. Kato T, Kume A, Ito K, Tadokoro M, Takahashi A, Sakuma S. Asymmetrical FDG-PET and MRI findings of striatonigral system in multiple system atrophy with hemiparkinsonism. Radiat Med. 1992;10:87-93.

35. Warmuth-Metz M, Naumann M, Csoti I, Solymosi L. Measurement of the midbrain diameter on routine magnetic resonance imaging: a simple and accurate method of differentiating between Parkinson disease and progressive supranuclear palsy. Arch Neurol. 2001;58:1076-9.

36. Landis J, Koch G. The measurement of observer agreement for categorical data. Biometrics. 1977;33:159-74.

37. Drayer BP, Olanow W, Burger P, Johnson GA, Herfkens R, Riederer S. Parkinson plus syndrome: diagnosis using high field MR imaging of brain iron. Radiology. 1986;159:493-8.

38. Naka $\mathrm{H}$, Imon $\mathrm{Y}$, Ohshita $\mathrm{T}$, et al. Magnetization transfer measurements of brain structures in patients with multiple system atrophy. Neuroimage. 2002;17:1572-8.

39. Nicoletti G, Fera F, Condino F, et al. MR imaging of middle cerebellar peduncle width: differentiation of multiple system atrophy from Parkinson disease. Radiology. 2006;239:825-30.

40. Pastakia B, Polinsky R, Di Chiro G, Simmons JT, Brown R, Wener L. Multiple system atrophy (Shy-Drager syndrome): MR imaging. Radiology. 1986;159:499-502.

41. Righini A, Antonini A, De Notaris R, et al. MR imaging of the superior profile of the midbrain: differential diagnosis between progressive supranuclear palsy and Parkinson disease. AJNR Am J Neuroradiol. 2004;25:927-32.

42. Lee JY, Yun JY, Shin CW, Kim HJ, Jeon BS. Putaminal abnormality on 3-T magnetic resonance imaging in early parkinsonismpredominant multiple system atrophy. J Neurol. 2010;257: 2065-70.

43. Ito $\mathrm{M}$, Watanabe $\mathrm{H}$, Kawai $\mathrm{Y}$, et al. Usefulness of combined fractional anisotropy and apparent diffusion coefficient values for detection of involvement in multiple system atrophy. J Neurol Neurosurg Psychiatry. 2007;78:722-8.

44. Schrag A, Good CD, Miszkiel K, et al. Differentiation of atypical parkinsonian syndromes with routine MRI. Neurology. 2000;54: 697-702.

45. Lee WH, Lee CC, Shyu WC, Chong PN, Lin SZ. Hyperintense putaminal rim sign is not a hallmark of multiple system atrophy at 3T. AJNR Am J Neuroradiol. 2005;26:2238-42.
46. Watanabe $\mathrm{H}$, Ito $\mathrm{M}$, Fukatsu $\mathrm{H}$, et al. Putaminal magnetic resonance imaging features at various magnetic field strengths in multiple system atrophy. Mov Disord. 2010;25:1916-23.

47. Watanabe H, Saito Y, Terao S, et al. Progression and prognosis in multiple system atrophy: an analysis of 230 Japanese patients. Brain. 2002;125:1070-83.

48. Shrivastava A. The hot cross bun sign. Radiology. 2007;245:606-7.

49. Takao M, Taro K, Tomita Y, Yoshida Y, Mihara B. 'Hot-cross bun sign' of multiple system atrophy. Intern Med. 2007;46:1883.

50. Burk K, Skalej M, Dichgans J. Pontine MRI hyperintensities ("the cross sign") are not pathognomonic for multiple system atrophy (MSA). Mov Disord. 2001;16:535.

51. Murata Y, Yamaguchi S, Kawakami H, et al. Characteristic magnetic resonance imaging findings in Machado-Joseph disease. Arch Neurol. 1998;55:33-7.

52. Ngai S, Tang YM, Du L, Stuckey S. Hyperintensity of the middle cerebellar peduncles on fluid-attenuated inversion recovery imaging: variation with age and implications for the diagnosis of multiple system atrophy. AJNR Am J Neuroradiol. 2006;27: 2146-8.

53. Loesch DZ, Cook M, Litewka L, et al. A low symptomatic form of neurodegeneration in younger carriers of the FMR1 premutation, manifesting typical radiological changes. J Med Genet. 2008;45: $179-81$

54. Okamoto K, Tokiguchi S, Furusawa T, et al. MR features of diseases involving bilateral middle cerebellar peduncles. AJNR Am J Neuroradiol. 2003;24:1946-54.

55. Asato R, Akiguchi I, Masunaga S, Hashimoto N. Magnetic resonance imaging distinguishes progressive supranuclear palsy from multiple system atrophy. J Neural Transm. 2000;107: 1427-36.

56. Kato N, Arai K, Hattori T. Study of the rostral midbrain atrophy in progressive supranuclear palsy. J Neurol Sci. 2003;210:57-60.

57. Wang Y, Butros SR, Shuai X, et al. Different iron-deposition patterns of multiple system atrophy with predominant parkinsonism and idiopathetic parkinson diseases demonstrated by phase-corrected susceptibility-weighted imaging. AJNR Am J Neuroradiol. 2012;33:266-73.

58. Sakurai K, Kawaguchi T, Kawai T, et al. Usefulness of 3DPRESTO imaging in evaluating putaminal abnormality in parkinsonian variant of multiple system atrophy. Neuroradiology. 2009;6:6.

59. Gupta D, Saini J, Kesavadas C, Sarma PS, Kishore A. Utility of susceptibility-weighted MRI in differentiating Parkinson's disease and atypical parkinsonism. Neuroradiology. 2010:52: 1087-94.

60. Arabia G, Morelli M, Paglionico S, et al. An magnetic resonance imaging $\mathrm{T} 2 *$-weighted sequence at short echo time to detect putaminal hypointensity in Parkinsonisms. Mov Disord. 2010; 25:2728-34.

61. Pellecchia MT, Barone P, Mollica C, et al. Diffusion-weighted imaging in multiple system atrophy: a comparison between clinical subtypes. Mov Disord. 2009;24:689-96.

62. Kanazawa M, Shimohata T, Terajima K, et al. Quantitative evaluation of brainstem involvement in multiple system atrophy by diffusion-weighted MR imaging. J Neurol. 2004;251:1121-4.

63. Taoka $T$, Kin $T$, Nakagawa $H$, et al. Diffusivity and diffusion anisotropy of cerebellar peduncles in cases of spinocerebellar degenerative disease. Neuroimage. 2007;37:387-93.

64. Morelli M, Arabia G, Novellino F, et al. MRI measurements predict PSP in unclassifiable parkinsonisms: a cohort study. Neurology. 2011;77:1042-7. 


\section{Appendix: Clinical Criteria for diagnosis of Parkinsonian Syndromes}

For the purpose of this study we have used the most commonly used diagnostic criteria or suggested modifications of the same in each of the disorders. We have however modified the criteria in some cases at the beginning of the study so as to include more recent knowledge about the disorders and also with a hope to be able to classify more of the cases which would have been excluded by some of the more stringent criteria.

\section{$\underline{\text { A }) ~ P S P ~-~ N I N D S ~ C l i n i c a l ~ r e s e a r c h ~}$ criteria $^{28}$ and SIC modifications ${ }^{29}$}

Mandatory Inclusion Criteria

a. Gradually progressive disorder

b. Age at onset at 40 or later

c. For.....

Possible (clinically probable $)^{29}$ - either vertical supranuclear palsy or both slowing of vertical saccades \& postural instability with falls $<1$ yr disease onset

Probable (clinically definite) ${ }^{29}$ - Vertical supranuclear palsy and prominent postural instability with falls within first year of disease onset

Definite - All criteria for possible or probable PSP are met and histopathologic confirmation at autopsy

Exclusion Criteria - For possible and probable:

1 . Recent history of encephalitis;

2. Alien limb syndrome;

3. Cortical sensory deficits;

4. Focal frontal or temporoparietal atrophy;

5. Hallucinations or delusions unrelated to dopaminergic therapy;

6. Cortical dementia of Alzheimer type;

7. Prominent, early cerebellar symptoms or unexplained dysautonomia;

8. or evidence of other diseases that could explain the clinical features

Supportive criteria

1. Symmetric akinesia or rigidity, proximal more than distal

2. Abnormal neck posture, especially retrocollis;

3. Poor or absent response of parkinsonism to levodopa;

4. Early dysphagia \& dysarthria;

5. Early onset of cognitive impairment including $>2$ of: apathy, impairment in abstract thought, decreased verbal fluency, utilization or imitation behavior, or frontal release signs

Clinical criteria ${ }^{29}$

1. Clinically Definite as the old probable

2. Clinically Probable as the old possible

3. New Category of Clinically Possible PSP as

a. Gradually progressive disorder

b. Onset over 40 years of age

c. Clear slowing of vertical downward saccades and marked abnormalities of vertical OKN\#

d. Postural instability/ disequilibrium within the first year (falls are unnecessary)

e. No exclusion criteria

"We have made one change to the SIC recommendations adding slowing of downward saccades and abnormalities of vertical OKN with the presence of postural instability within the first year without mandating the presence of falls for the diagnosis of PSP as previously required in the SIC modifications.

B MSA - Consensus criteria for the diagnosis of $\mathrm{MSA}^{30}$

Section ONE - features and criteria

I. Autonomic and urinary dysfunction

A. Autonomic and urinary features.

Orthostatic hypotension (by $20 \mathrm{~mm} \mathrm{Hg}$ systolic or $10 \mathrm{~mm} \mathrm{Hg}$ diastolic); urinary incontinence or incomplete bladder emptying

B. Criterion for autonomic failure or urinary dysfunction in MSA.

Orthostatic fall in blood pressure (by $30 \mathrm{~mm} \mathrm{Hg}$ systolic or $15 \mathrm{~mm} \mathrm{Hg}$ diastolic) and/or urinary incontinence (persistent, involuntary partial or total bladder emptying, accompanied by erectile dysfunction in men)

\section{Parkinsonism;}

\section{A. Parkinsonian features}

1) Bradykinesia (slowness of voluntary movement with progressive reduction in speed and amplitude during reciprocal actions)

2) Rigidity

3) Postural instability (not caused by primary visual, vestibular, cerebellar or proprioceptive dysfunction

4) Tremor (postural, resting or both) 
B. Criteria for Parkinsonism in MSA

Bradykinesia plus at least one of items of 2-4

III. Cerebellar dysfunction;

A. Cerebellar features

1) Gait ataxia;

2) Ataxic dysarthria;

3) Limb ataxia;

4) Sustained gaze-evoked nystagmus

B. Criterion for Cerebellar dysfunction

Gait ataxia plus at least one of items of 2-4

IV. Corticospinal tract dysfunction

A. Corticospinal tract features

Extensor plantar responses + Hyperreflexia;

B. No corticospinal tract features are used in defining the diagnosis of MSA

V. Set of softer features ${ }^{\#}$

a) REM sleep behavior disorder

b) Stidor

c) Myocolonus

d) Severly hypophonic speech

e) Marked antecollis (head drop)

\section{Section TWO: Diagnosis of probable and possible MSA}

Possible MAJOR: One criterion plus two features from separate other domains. When the criterion is Parkinsonism, a poor levodopa response qualifies as one feature (hence, only one additional feature is required)

Possible MINOR: Same as the above - however $\geq 2$ softer features may be substituted as one feature in the above criteria

Probable A: One criterion for autonomic failure/urinary dysfunction plus poorly levodopa responsive Parkinsonism or cerebellar dysfunction

Probable a: autonomic feature + Parkinsonism criteria + cerebellar feature $+\geq 2$ softer features

Definite: Pathologically confirmed by the presence of a high density of glial cytoplasmic inclusions in association with a combination of degenerative changes in the nigrostriatal and olivopontocerebellar pathways

\section{Section THREE: Exclusion criteria}

For possible and probable:

History

1. Symptomatic onset $<30 \mathrm{yr}$ of age

2. Family history of a similar disorder;

3. Systemic diseases or other identifiable causes for features listed above

4. Hallucinations unrelated to medication

Clinical examination

5. DSM criteria for dementia;

6. Prominent slowing of vertical saccades or vertical supranuclear gaze palsy

7. Evidence of focal cortical dysfunction such as aphasia, alien limb syndrome, and parietal dysfunction

Laboratory Investigation

8. Metabolic, molecular genetic, and imaging evidence of an alternative cause of features listed above.

${ }^{\#}$ We added a set of softer features recommended by the SIC in their evaluation of Criteria for MSA ${ }^{29}$ with the aim to pick up the diagnosis and classify more earlier presentations of the disease.

\section{C) Cortico-basal Degeneration (CBD) Diagnostic Criteria by Boeve et $\mathrm{al}^{27}$}

Core features

- Insidious onset and progressive course

- No identifiable cause (e.g. tumor; infarct)

- Cortical dysfunction as reflected in at least one of the following 
o Focal or asymmetrical limb apraxia

o Alien limb phenomenon

o Cortical sensory loss

o Visual or sensory neglect

o Constructional apraxia

o Focal or asymmetric myoclonus

o Apraxia of speech/ nonfluent aphasia

-Extrapyramidal dysfunction as reflected by at least one of the following

o Focal or asymmetrical appendicular limb rigidity lacking prominent and sustained L Dopa response

o Focal or asymmetrical appendicular dystonia

Supportive investigations

- Variable degrees of focal or lateralized cognitive dysfunction, with relative preservation of learning and memory, on neuropychometric testing

- Focal or asymmetric atrophy on computed tomography or magnetic resonance imaging, typically maximal in parietofrontal cortex

- Focal or asymmetric hypoperfusion on single-photon emission computed tomography and positron emission tomography, typically

maximal in parietofrontal cortex $+/$ - basal ganglia $+/$ - thalamus

D \} Parkinson's disease (PD) - as per the UKPDS Brain bank Criteria ${ }^{31}$

Step 1 - Diagnosis of Parkinsonism

Bradykinesia and at least one of the following

- Bradykinesia

- Muscular rigidity

- 4-6 Hz. Resting tremor

- Postural instability not caused by primary visual, vestibular, cerebellar or Proprioceptive dysfunction

Step 2 - Features tending to exclude Parkinson's disease as a cause of the Parkinsonism\#

1. History of repeated strokes with stepwise progression of parkinsonian features

2. History of repeated head injury

3. History of definite encephalitis

4. Neuroleptic treatment at onset of symptoms

5. Sustained remission

6. Strictly unilateral features after 3 years

7. Supranuclear gaze palsy

8. Cerebellar signs

9. Early severe autonomic involvement

10. Early severe dementia with disturbances of memory, language and praxis

11. Babinski's sign

12. Presence of a cerebral tumour or communicating hydrocephalus on computed tomography scan

13. Negative response to large doses of levodopa (if malabsorption excluded)

14. MPTP exposure

\# The criteria of ' $>1$ affected relatives' as an exclusion criteria was removed

Step 3 - Features that support a diagnosis of Parkinson's disease (three or more required for diagnosis of definitive Parkinson's disease)

1. Unilateral onset

2. Rest tremor present

3. Progressive disorder

4. Persistent asymmetry affecting the side of onset most

5. Excellent $(70-100 \%)$ response to levodopa

6. Severe levodopa-induced chorea

7. Levodopa response for $\geq 5$ years

8. Clinical course of $\geq 10$ years 


\section{Supplementary Data}

65. Canu E, Agosta F, Baglio F, Galantucci S, Nemni R, Filippi M. Diffusion tensor magnetic resonance imaging tractography in progressive supranuclear palsy. Mov Disord. 2011;26:1752-5

\section{METHODS}

Controls included 21 cases who had undergone MRI scans of the brain for the complaints of headaches, 16 for transient neurological deficits including sensory and motor complaints, seven with vertigo, five with cranial nerve related symptoms including earache and vision impairment, five with history of head injuries, four with episodes of loss of consciousness, four with requests to look for space occupying lesions, and two for screening due to familial disorders. All the MRI scans had previously reported as normal.

In most cases the following sequences were acquired (in the axial plane except for the $T_{1}$ sequence): $T_{1}$-weighted images were acquired using a conventional spin echo with the following parameters: repetition time $500 \mathrm{msec}$, echo time $8 \mathrm{msec}$, slice thickness of $5 \mathrm{~mm}$, slice gap of $2 \mathrm{~mm}$, field of view (FOV) 240mm, matrix 256 X192; $\mathrm{T}_{2}$-weighted images were acquired with fast spin echo (FSE) with the following parameters: repetition time 4,450 msec, echo time $90 \mathrm{msec}$, slice thickness of $5 \mathrm{~mm}$, slice gap of $2 \mathrm{~mm}$, FOV 220mm, matrix 256 X 256, echo train length of 17. FSE images were obtained using the following parameters: repetition time $10,000 \mathrm{msec}$, echo time $150 \mathrm{msec}$, inversion time $2200 \mathrm{msec}$, slice thickness of $5 \mathrm{~mm}$, slice gap of $2 \mathrm{~mm}$, FOV 220mm, matrix $256 \mathrm{X}$ 192. DWI imaging was recorded using spin-echo echoplanar imaging (EPI) sequence with the following parameters: b-value of $1000 \mathrm{~s} / \mathrm{mm}^{2}$, repetition time $8,000 \mathrm{msec}$, echo time $63 \mathrm{msec}$, slice thickness of $5 \mathrm{~mm}$, no gap, FOV 260mm, matrix 128 X 128s. GRE imaging was recorded using a gradient-echo EPI sequence ${ }^{2}$ and the following parameters: repetition time $4,000 \mathrm{msec}$, echo time $30 \mathrm{msec}$ at $1.5 \mathrm{~T} 25 \mathrm{msec}$ at $3 \mathrm{~T}$, slice thickness of $5 \mathrm{~mm}$, no gap, FOV $240 \mathrm{~mm}$, matrix 256 X $384 \mathrm{~s}$

\section{RESULTS}

Among raters moderate agreement was found for the presence of putamen hypointensity on GRE scans, with complete agreement within the same rater when rated at different time points (supplementary Table 2).

Brief case reports of patients not fulfilling diagnostic criteria for MSA-P but who had putamenal atrophy and GRE hypointensity.

One undiagnosed patient (case 195) was a 66-year-old gentleman with asymmetric parkinsonism of three year duration with a poor response to L-Dopa. He had a jerky tremor, erectile

Supplementary Figure: Region of Interest mapping for ADC. T2 axial $(a, c, e)$ and corresponding $A D C$ images $(b, d, f)$ showing the calculation of $A D C$ values in patients. The ROIs were applied to the area of the putamen $(b)$, Middle cerebellar peduncle $(d)$ and the lateral ventricles bilaterally for the calculation of mean $A D C$ of the region of interest using the corresponding T2 axial images for anatomical reference. dysfunction and marked constipation. He had no urinary incontinence or orthostatic symptoms. He did not fulfill criteria for MSA at the time of assessment. The second patient (case 22) was a 53-year-old lady with tremor dominant symptoms who fulfilled criteria for PD. She had been followed for four years after disease onset. Apart from a jerky tremor and some stimulus sensitive myoclonus in the fingers, there were no other atypical features. She had been on a very low dose of L-Dopa due to nausea making an assessment of her response difficult. The last patient (case 37) fulfilled the criteria for PSP. He was an 80-yearold gentleman with L-Dopa unresponsive akinetic rigid state with early falls, abnormal extraoccular movements and bulbar involvement.

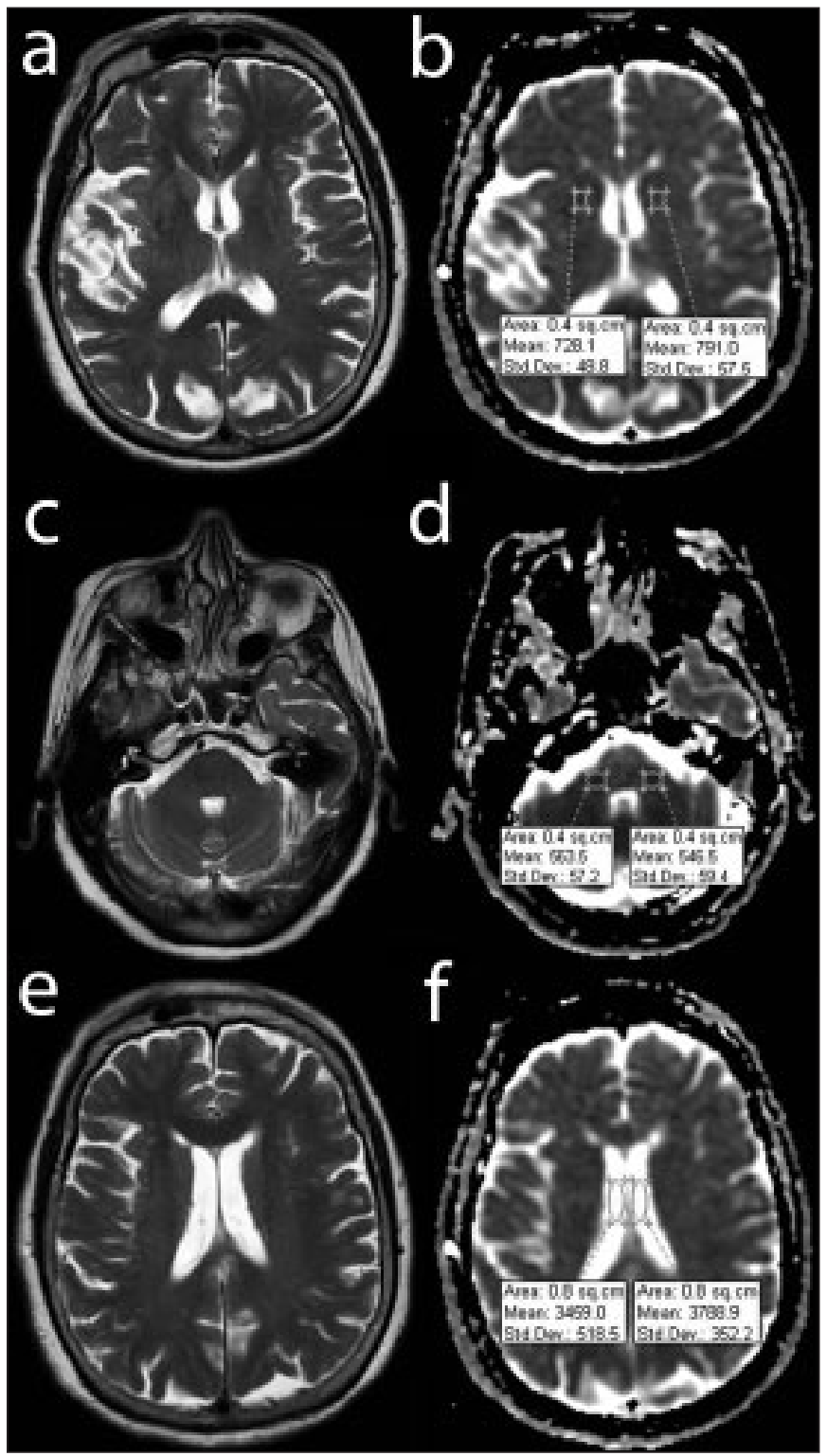




\section{Supplementary Table 1: Signs on T1/ T2 MRI}

\begin{tabular}{|c|c|c|c|c|c|c|c|c|c|}
\hline Characteristic & CBS & Control & MSA-C & MSA-P & PD & PSP & Undiagnosed & Total & Significance \\
\hline Number of cases & 6 & 64 & 7 & 15 & 61 & 21 & 21 & 195 & \\
\hline $\mathrm{T}_{2}$ Atrophy of putamen (\%) & $1(16.7)$ & $4(6.3)$ & $3(42.9)$ & $11(71.3)$ & $16(26.2)$ & $11(52.4)$ & $7(31.3)$ & $54(24.6)$ & $<0.0001$ \\
\hline $\mathrm{T}_{2}$ hypointensity of putamen ${ }^{\mathrm{a}, \mathrm{b}}(\%)$ & $1(16.7)$ & $2(3.1)$ & 0 & $6(40)$ & $6(9.8)$ & $2(9.5)$ & $2(9.5)$ & $19(9.7)$ & 0.013 \\
\hline slit-like hyperintensity of putamen ${ }^{\mathrm{a}, \mathrm{b}}(\%)$ & $0(0)$ & $3(4.7)$ & $0(0)$ & $9(60)$ & $4(6.6)$ & $3(14.3)$ & $5(23.8)$ & $26(13.3)$ & $\mathrm{p}<0.0001$ \\
\hline Presence of Humming-bird sign (\%) & 0 & 0 & 0 & $3 \quad(20)$ & $5 \quad(8.2)$ & $10(47.6)$ & $2(9.5)$ & $20(10.3)$ & $\mathrm{p}<0.0001$ \\
\hline Presence of morning glory sign (\%) & 0 & 0 & 0 & 0 & 0 & $2(9.5)$ & $1(4.8)$ & $3(1.5)$ & $\mathrm{p}<0.0001$ \\
\hline 'resence of the Hot-cross-bun sign ${ }^{\mathrm{c}}(\%)$ & 0 & 0 & $5(71.4)$ & $2(13.3)$ & 0 & $2(9.5)$ & $1(4.8)$ & $10(5.1)$ & $\mathrm{p}<0.0001$ \\
\hline 'resence of hyperintensity of $\mathrm{MCP}^{\mathrm{c}}(\%)$ & $1(16.7)$ & 0 & $3(42.9)$ & $2(13.3)$ & 0 & 0 & $1(4.8)$ & $7(3.6)$ & $\mathrm{p}<0.0001$ \\
\hline Aean pontine AP diameter +/- SD (mm) & $2.25+/-0.18$ & $2.32+/-0.14$ & $1.94+/-0.21$ & $2.16+/-0.23$ & $2.36+/-0.15$ & $2.19+/-0.18$ & $2.26+/-0.17$ & $2.28+/-0.19$ & $\mathrm{p}<0.0001$ \\
\hline
\end{tabular}

$\mathrm{CBS}=$ Corticobasal syndrome, $\mathrm{MSA}-\mathrm{C}=$ Multiple system atrophy cerebellar type, $\mathrm{MSA}-\mathrm{P}=$ Multiple system atrophy parkinsonian type, $\mathrm{PD}=$

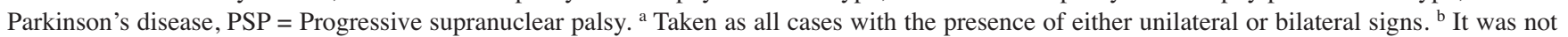
possible to assess the characteristics in 2 cases of PD due to technical difficulties. (denominator for PD was 59, total cases 193 ) ${ }^{\mathrm{c}}$ It was not possible to assess the characteristics in 1 case with PD due to technical difficulties. (denominator for PD was 60)

\section{Supplementary Table 2: Intra-rater and inter-rater reliability analysis of the different signs}

\begin{tabular}{c|c|c}
\hline Variable & ${\text { Intra-rater reliability }- \text { kappa value }^{\mathrm{a}}}$ & ${\text { Inter-rater reliability }- \text { kappa value }^{\mathrm{b}}}$ \\
\hline${\text { Atrophy of putamen on } \mathrm{T}_{2}^{\mathrm{c}}}_{\mathrm{T}_{2} \text { Hypointensity of Putamen }^{\mathrm{c}}}$ & 0.5758 & 0.5205 \\
\hline $\mathrm{T}_{2}$ Slit-like hyperintensity of putamen $^{\mathrm{c}}$ & 0.4167 & 0.7143 \\
\hline Hummingbird sign & 0.5758 & 0.5946 \\
\hline Loss of tegmental convexity & 1.0 & 0.6364 \\
\hline Hot cross bun sign & 1.0 & 1.0 \\
\hline Hyperintensity of MCP & 1.0 & 0.7671 \\
\hline GRE Hypointensity of putamen & 1.0 & 0.6364 \\
\hline
\end{tabular}

$\mathrm{GRE}=$ gradient echo imaging, $\mathrm{MCP}=$ mid dle cerebellar peduncle. ${ }^{\text {a }} 31$ scans rated by each of the two blinded raters twice. ${ }^{\mathrm{b}} 14$ scans rated by the two blinded raters twice at different time points. ${ }^{\mathrm{c}}$ Taken as all cases with the presence of either unilateral or bilateral signs. Interpretation of kappa values: 0.4-0.59 mod agreement; 0.6-0.79 substantial agreement, 0.8-1.0 outstanding agreement.

\section{Supplementary Table 3: Distribution of undiagnosed cases and role of MRI}

\begin{tabular}{|c|c|c|c|}
\hline Clinical Syndrome among the undiagnosed group & $\mathbf{N}$ & $\begin{array}{l}\text { No. with relevant } \\
\text { MRI signs }\end{array}$ & Description of relevant abnormal MRI Scans \\
\hline Parkinsonism with autonomic features not fitting MSA criteria & 4 & 2 & $\begin{array}{l}\text { Case } 195^{\mathrm{a}} \text { had GRE hypointensity and atrophy of the putamen on two MRI scans a } \\
\text { year apart. Case } 147^{\mathrm{b}} \text { had a hot cross bun sign and } T_{2} \text { hyperintensity of the MCP }\end{array}$ \\
\hline Sporadic ataxia not fitting criteria for MSA & 4 & 2 & $\begin{array}{c}\left.2 \text { (case } 35^{\mathrm{c}}, 81^{\mathrm{d}}\right) \text { had significantly higher rADC values in the MCP compared to the } \\
\text { cut off value }\left(0.94 \times 10-3 \mathrm{~mm}^{2} / \mathrm{sec}\right)\end{array}$ \\
\hline $\begin{array}{c}\text { Parkinsonism with predominant gait disturbance and postural instability not fulfilling criteria } \\
\text { of PD or PSP }\end{array}$ & 9 & 2 & $\begin{array}{c}2 \text { showed the presence of a hummingbird sign }\left(\text { case } 1^{\mathrm{e}}, 176^{\mathrm{f}}\right), \\
\text { case } 1 \text { also had a morning glory sign }\end{array}$ \\
\hline Corticobasal like syndrome not fulfilling criteria & 3 & 0 & \\
\hline Asymmetric Parkinsonism with a resting tremor not fulfilling criteria for PD yet. & 1 & 0 & \\
\hline Total Undiagnosed cases & 21 & 6 & \\
\hline
\end{tabular}

CBS = Corticobasal syndrome, MSA = Multiple system atrophy, $\mathrm{PD}=$ Parkinson's disease, $\mathrm{PSP}=$ Progressive supranuclear palsy GRE $=$ gradient echo imaging, $\mathrm{MCP}=$ middle cerebellar peduncle. ${ }^{\text {aC Case }} 195$ was a 66 year old gentleman with asymmetric parkinsonism of three year duration with a poor response to L-Dopa. He had a jerky tremor, erectile dysfunction and marked constipation. He had no urinary incontinence or orthostatic symptoms. He did not fulfill criteria for MSA at the time of assessment. ${ }^{\mathrm{b}}$ Case 147 was a 60 year old lady presenting with parkinsonism with a right foot tremor. She also had ataxia and mild autonomic dysfunction not fulfilling the criteria for MSA. She had a long disease course with stridor. ${ }^{\mathrm{C} C a s e} 35$ had asymmetric parkinsonism with mild autonomic features and dementia in addition to ataxia. He died within 4 years of his illness. ${ }^{\mathrm{d}} \mathrm{Case} 81$ had ataxia with no autonomic features or parkinsonism. ${ }^{\mathrm{e}} \mathrm{Case} 1 \mathrm{had}$ forward falls, forgetfulness, diminished vertical saccades and pursuits and parkinsonism. He also had urinary incontinence and enlarged ventricles on the MRI raising the question of NPH, though clinically he had more features of PSP. ${ }^{\mathrm{f}}$ Case 176 had L-Dopa unresponsive parkinsonism, with early forward falls, dysphagia, dementia, urinary incontinence, postural rather than resting tremors. Over 3 years she progressed to an akinetic rigid mute state with dementia. Her vertical gaze was restricted. 